\title{
Gender differences in the activity of the autonomic nervous systems of healthy and hypertensive patients in Russia
}

\begin{abstract}
Objective: Evaluation of the gender difference in the activity of the autonomic nervous systems of healthy and hypertensive patients in Russia.

Materials and Methods: The methods of heart rate variability (HRV) and gas discharge visualization (GDV or electrophotonic Imaging/EPI) were used to assess subjects. Analysis of data from 138 patients with different stages of arterial hypertension, aged 20 to 70 years, and 37 healthy ones was carried out.

Results: The differences in the activity of the autonomic nervous system in men and women, both healthy subjects and those suffering from arterial hypertension were detected. The offset of autonomic balance toward the predominance of the sympathetic nervous system was observed in most healthy men and women suffering from arterial hypertension, regardless of their age.

Conclusion: The difference in parameters was not due to hyperactivity of the sympathetic center, but due to a lower parasympathetic activity. For the majority of hypertensive and healthy women, the autonomic balance shifted toward predominance of the parasympathetic nervous system.
\end{abstract}

Keywords: arterial hypertension, autonomic nervous system, heart rate variability, gas discharge visualization
Volume 3 Issue 6 - 2017

\author{
Korobka IE,' Yakovleva EG,' Belonosov SS,' \\ Zarubina TV,' Korotkov KG² \\ 'Pirogov Russian National Research Medical University, Russia \\ ${ }^{2}$ Department of mechanics and Optics, St Petersburg Research \\ Institute of Physical Culture and Sport, Russia
}

\begin{abstract}
Correspondence: Konstantin G Korotkov, Department of mechanics and Optics, Saint Petersburg Federal University of Information Technologies, St Petersburg Research Institute of Physical Culture and Sport, NIIFK, Ligovski prospect 56E, St. Petersburg, 19104, Russia, Fax +7-81260041 17, Tel +79219368394, Email korotkov2000@gmail.com
\end{abstract}

Received: March 23, 2017 | Published: September 08, 2017

\begin{abstract}
Abbreviations: HRV, heart rate variability; GDV, gas discharge visualization; EPI, electrophotonic imaging; ANS, autonomic nervous system; CCD, charge couple device; HF, high frequency; LF, low frequency; $\mathrm{AH}$, arterial hypertension; $\mathrm{VR}$, variation range

\section{Introduction}

The idea of arterial hypertension (AH) as a neurogenic disease was put forward in 1922 by the Soviet scientist Lang GF Till date; a large amount of evidence about the role of autonomic disorders in the development and formation of AH has been collected. Special attention is paid to the increase in the tone of the sympathetic nervous system. ${ }^{1-3}$ The results of one of the largest studies on this topic (Tecumseh Blood Pressure Study $^{4}$ ) provided strong evidence that activation of the sympathetic link of the autonomic nervous system (ANS) is important not only in the early stages of the development of hypertension, but contributes to the formation of cardiovascular risk in the future. At the same time, there are indications of gender dimorphism in the autonomic regulation of a healthy body, ${ }^{5-10}$ which, in turn, determines the peculiarities of the development of hypertension in men and women. With a high predisposition to hypertension in healthy men, blood circulation at rest is determined primarily by increased influence of the sympathetic division of the ANS. But among apparently healthy women having a high predisposition to hypertension, blood circulation depend to a lesser extent on the specifics of the autonomic regulation compared to men. ${ }^{11}$ However, despite existing data, which indicate different mechanisms of formation and establishment of hypertension in men and women, the amount of experimental data is not yet sufficient. ${ }^{12}$ In this connection, the aim of this work was to evaluate the gender-specific state of the autonomic nervous system of healthy people and hypertensive patients, using the methods of heart rate variability (HRV) and gas discharge visualization (GDV).

\section{Materials and methods}

To assess the state of the autonomic nervous system of patients, the methods of heart rate variability (HRV) ${ }^{13}$ and gas discharge visualization (GDV or Electrophotonic Imaging) ${ }^{14-16}$ were applied. In the HRV method, the heart rhythm is recorded, with a subsequent mathematical analysis of its structure. Main HRV indexes are presented in Table 1. The index of regulatory systems tension (stress index SI) is calculated based on histogram of distribution of cardio intervals as random variables. The amplitude of every bar of the histogram is equal to the amount of RR intervals with particular duration. From the histogram its basic characteristics: mode Mo, mode amplitude (AMo) and variation range (VR) are determined. When during mental or physical loading we have increase of the sympathetic regulation it leads to stabilization of the heart rhythm caused by participation in the cardiac activity of the higher (central) levels of regulation, which leads to a decrease in the distribution of cardio intervals durations, i.e. increase of number of intervals of similar duration (AMo increases). The shape of the histogram is changing its constriction occurs with a simultaneous increase in height. The stress index SI is calculated in accordance as following:

\section{$\mathrm{SI}=\mathrm{AMo} * \mathrm{VR} / 2 \mathrm{Mo}$}

The normal range of SI is $80-150$ units.

People were recommended for 1.5-2 hours before the examination do not eat, do not smoke, do not drink coffee, strong tea, during the 
HRV measurement do not take a deep breath, coughing, swallowing. A survey of patients was conducted in the morning in a darkened room, with the elimination of emotional arousal factors, including conversation and phone calls. Women were measured in the intermenstrual period. Before measurement patients rested for 5-10 minutes in a horizontal position. The HRV study included a 5-minute ECG recording (no less than 300 cardiocycles) in the supine position during quiet breathing. After this GDV testing was performed this lasted about 5 minutes. GDV bioelectrography (Electrophotonic Imaging EPI ${ }^{14,15}$ ) is already utilized in 62 countries, with great success. This effect occurs when an object is placed on a glass plate and stimulated with a high-intensity electrical field; a visible glow occurs, produced by the gas discharge. This glow is detected by a sensitive CCD camera and processed in the computer as a digital image. In the EPI technology, images captured of all 10 fingers on each human subject provide a set of quantitative parameters, which may be used for statistical analysis and practical applications. EPI applications in different areas are being developed. ${ }^{14-30}$

The parameters of the image generated from photographing the finger surface under electrical stimulation create a neurovascular reaction on part of the skin, influenced by the nervous-humoral status of organs and systems. Owing to this, the images captured on the GDV/EPI register an ever-changing range of states. In addition, the EPI readings of most healthy people vary only $8-10 \%$ over many years of measurements, indicating a high level of precision in this technique. ${ }^{14,15} \mathrm{~A}$ total of 138 people, aged 20 to 70 years were surveyed. Among them, 37 healthy ones, between them 15 men mean age $50.5 \pm 9.0$ and 22 women mean age $50.1 \pm 11.2$ comprised the control group, and 101-AH patients, between them 50 men mean

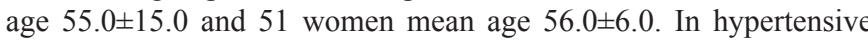
patients, 34 persons had hypertension Stage I (blood pressure: Sys 120-139; Diast 81-89), 46-AH Stage II (Sys 140-159; Diast 90-99) and 21-AH Stage III (Syst $>160$; Diast $>100$ ). Some $70 \%$ of patients with hypertension constantly took medications to lower blood pressure. On the day prior to the study, medications were canceled.

HRV and GDV readings were carried out for each patient sequentially, in the first half of the day, not earlier than 1.5-2 hours after food. The time interval between the methods was $5-7 \mathrm{~min}$. For the HRV analysis, the device "Polispektr" ("Neurosoft," Russia www. neurosoft.ru/eng/) was used. The entry consisted of 5 minutes of ECG recording (no less than 300 cardio cycles) in the supine position. The study included only patients with sinusoidal rhythm without the presence of frequent extra systoles. The HRV indexes used for statistical processing are presented in Table 1. For the GDV analysis, the devices "GDV Pro" and "Bio-Well" were used. Device GDV Pro and Bio-Well use the same hardware, and the difference that in the GDV Pro device data processing is done by software installed to the computer, while in the Bio-Well device data processing is done by more sophisticated software on server. Special experiments demonstrated that parameters measured by these two devices at the same time on the same subjects generate similar parameters.

\section{In this paper we are using two main parameters}

The integral area is an amount of light quanta generated by the subject in computer unit's pixels (the number of pixels in the image having brightness above the threshold). We are using both the total area of all 10 fingers and the area of fingers of the left and right hands separate (Table 2). Stress coefficient is calculated as the ratio between the total area of the particular subject and the total area of the ideal healthy person, calculated from statistics of 8000 people. ${ }^{14-16}$ Statistical processing of the results was done in Excel, SPSS Statistics 17.0 and Statistica 7.0 programs. Statistical distribution of the HRV and GDV parameters tested with the Kolmogorov Smirnov test did not follow normal law. Therefore, non-parametric Mann Whitney U-criterion was used for data analysis. The Institutional Review Board approval for the study of the Pirogov Russian National Research Medical University, Moscow, Russia was obtained.

Table I HRV indicators

\begin{tabular}{|c|c|c|}
\hline Name & Index & Characteristics \\
\hline Total spectral power & $\mathrm{TP}\left(\mathrm{ms}^{2}\right)$ & The sum activity of neuro-humoral influences on heart rate \\
\hline $\begin{array}{l}\text { The relative importance of the power of high- } \\
\text { frequency waves }\end{array}$ & $\mathrm{HF}(\%)$ & $\begin{array}{l}\text { The activity of the parasympathetic center of the autonomic } \\
\text { nervous center }\end{array}$ \\
\hline $\begin{array}{l}\text { The relative importance of the power of low } \\
\text { frequency waves }\end{array}$ & LF (\%) & $\begin{array}{l}\text { The activity of the sympathetic centers of the autonomic nervous } \\
\text { center (cardio -stimulating and vasoconstrictor) }\end{array}$ \\
\hline $\begin{array}{l}\text { The relative importance of the power of very low } \\
\text { frequency waves }\end{array}$ & VLF (\%) & $\begin{array}{l}\text { The activity of the Central and humoral-metabolic mechanisms of } \\
\text { heart rate regulation }\end{array}$ \\
\hline Vegetative sympathetic index & $\mathrm{LF} / \mathrm{HF}$ & The ratio of sympathetic -parasympathetic effects \\
\hline Mode & Mo (sec) & The dominant level of the cardiac rhythm functioning \\
\hline $\begin{array}{l}\text { The mode amplitude - the relative number of cardio } \\
\text { intervals, corresponding to this mode }\end{array}$ & AMo (\%) & The stabilizing effect of centralization of heart rhythm regulation \\
\hline Variation Range & $\begin{array}{l}\text { VR } \\
\text { (relative } \\
\text { units) }\end{array}$ & The degree of variability of RR intervals \\
\hline $\begin{array}{l}\text { The index of regulatory systems tension (stress } \\
\text { index) }\end{array}$ & $\begin{array}{l}\text { SI (relative } \\
\text { units) }\end{array}$ & The degree of centralization of heart rhythm regulation \\
\hline
\end{tabular}


Table 2 GDV indicators

\begin{tabular}{lll}
\hline Name & Index & Characteristics \\
\hline $\begin{array}{l}\text { The total area of the } \\
\text { image }\end{array}$ & S (pixels) & $\begin{array}{l}\text { The functional } \\
\text { reserves of the body }\end{array}$ \\
$\begin{array}{l}\text { Stress coefficient } \\
\begin{array}{l}\text { The integral area } \\
\text { of luminescence of } \\
\text { fingers of the right } \\
\text { hand }\end{array}\end{array}$ & JSR (relative units) & $\begin{array}{l}\text { Stress level } \\
\text { The activity of the } \\
\text { autonomic nervous } \\
\text { The integral area } \\
\text { of luminescence of } \\
\text { fingers of the left hand }\end{array}$ \\
\hline
\end{tabular}

\section{Results and discussion}

At the beginning, a comparison was made of the control group (37 people) with a group of patients with hypertension (101 people) without gender difference. Averaged indicators are presented in Table 3. The data of the above table demonstrate that the values of the $\mathrm{LF} / \mathrm{HF}$ index both in the control group and in the group of patients with hypertension, when analyzed without gender difference, are within normal limits, and no significant difference between groups in relation to this indicator was found. However, it was revealed that the hypertensive patients differed from the control group in the stress index (SI), and, for $\mathrm{AH}$ patients, it exceeded the normal value. The same result was found for the GDV stress index. Furthermore, groups of healthy people and patients with hypertension were divided on the basis of gender, and compared differently. Table 4 shows the HRV and GDV indexes, with marked difference $(\mathrm{p}<0.05)$. As a result of this comparison, the difference on many indexes in both men and women were found.

In accordance with, ${ }^{2,3}$ hypertensive patients unlike healthy subjects have a high degree of centralization of heart rhythm regulation, i.e., the predominance of the central contour of the heart rhythm regulation (cerebral cortex, hypothalamus-pituitary and autonomic subcortical centers), on the autonomous contour (lungs, sinus node, the nucleus of the vagus nerve). Both for healthy men and men with hypertension, the $L F / H F$ index values exceeded the normal values $(\mathrm{LF} / \mathrm{HF}>2)$, indicating a shift in autonomic balance toward the predominance of the sympathetic nervous system. For healthy women and women with hypertension LF/HF index was below the norm $(\mathrm{LF} / \mathrm{HF}<1.5)$, indicating a shift of autonomic balance toward the predominance of the parasympathetic system. ${ }^{8-10}$

Thus, differences in LF/HF index in healthy men and women, as well as in patients with hypertension, whether men or women, indicate the necessity of considering gender when examining the patients, and subsequently choosing the treatment tactics. It is also important to note that for men, the relative values of the power of high frequency (HF) waves were significantly reduced compared to women. The difference in the HF indicator in men and women leads to the conclusion that for men both healthy ones and patients with hypertension the autonomic balance are shifted toward the predominance of the sympathetic nervous system. Apart from the difference in HRV indexes between men and women, significant differences in GDV parameters were revealed. The integral area of luminescence of the fingers of the right and left hands (JSR, JSL), and the total area of the image (S) had lower values in men compared to women, which also indicates a bias in men's autonomic balance toward the sympathetic nervous system. ${ }^{4}$ Comparison between healthy men and men patients, as well as between healthy women and women patients, confirmed the data of higher values of the stress index, presented in Table 3, for patients compared with healthy people.

Table 3 Comparison of the control group and the group of patients with hypertension on the autonomic sympathetic index and stress index without gender difference

\begin{tabular}{lcccc}
\hline Group & LF/HF & $\begin{array}{l}\text { LF/HF } \\
\text { norm* }\end{array}$ & SI & SI norm* \\
\hline Control & $1.68 \pm 0.8$ & & $86.31 \pm 50.2$ & \\
$\begin{array}{l}\text { AG } \\
\text { patients }\end{array}$ & $1.80 \pm 1.3$ & $1.5-2.0$ & & $80-150$ \\
\hline
\end{tabular}

The values of a norm is given in accordance with the "Standards of measurement, physiological interpretation and clinical use of heart rate variability" developed by experts of the European Association of cardiology and the North American Association of rhythmology and electrophysiology.

In addition to the high stress index, patients with hypertension, both men and women, had the higher values of the mode amplitude AMo, indicating a high stabilizing effect of centralization of heart rhythm regulation and decrease of the total spectral power (TP), indicating decrease in neuro-humoral influences on heart rate (Table 4). For women with hypertension, unlike healthy women, the relative value of the power of the low frequency waves (LF) was reduced (Table 4), which differentiates them from men with hypertension (Table 4). Also, the relative values of the power of high frequencies waves (HF) were reduced, while the relative power of very low frequency waves (VLF) was increased. These frequency ratios may indicate a less pronounced regulation of the heart rate by reflex autonomic level in women with hypertension and more pronounced regulation by low humoral-metabolic level, which is not able to provide homeostasis fast. However, despite lower activity of sympathetic (LF) and parasympathetic (HF) centers of the medulla oblongata in women with hypertension (compared with healthy women), autonomic balance shifted toward parasympathetic activity of the ANS (Table 4). Hypertensive women differed from healthy ones by lower GDV parameters, indicating the decrease in functional reserves of the organism and autonomic imbalance. ${ }^{4}$ The final phase of the study was to test the frequency of occurrence of high index LF/HF $>2$ (Figure 1) and increased index of tension of regulatory systems (SI>150) (Figure 1) among men and women, depending on age.

It is evident from the graphs that the rate of LF/HF in all age groups, in most cases, is higher for men than for women. Thus, of all men surveyed, $62.1 \%$ had high index LF/HF $>2$. Among women, only $25.0 \%$ had high $\mathrm{LF} / \mathrm{HF}$ value. To understand the reason for the increased index for $62.1 \%$ of men (healthy individuals and patients) and $25.0 \%$ of women (healthy individuals and patients), a comparative analysis of a group of men with normo-tone ( $\mathrm{LF} / \mathrm{HF}$ values from 1.5 to 2 ) and a group of men with sympathetic tone $(\mathrm{LF} / \mathrm{HF}>2)$, as well as groups of women with normo-tone and groups of women with sympathetic tone, was conducted (Table 5). It was found that for men and women with a sympathetic tone, the relative values of the power of high frequency waves $(\mathrm{HF})$ is significantly lower $(\mathrm{p}<0.05)$ compared with men and women with normo-tone. Thus, the LF/HF index for people with sympathetic tone of both genders is higher in 
comparison with normo-tone people due to the lower parasympathetic activity of the autonomic nervous system, but not at the expense of increased activity of the sympathetic one. The frequency of high SI index was practically the same for men $(51.5 \%)$ and women $(52.8 \%)$ (Figure 2).

Table $4 \mathrm{HRV}$ and GDV indices for healthy men and women (control group) and patients with hypertension

\begin{tabular}{|c|c|c|c|}
\hline Gender & Index & Control & AH patients \\
\hline \multirow{10}{*}{ Men } & LF/HF* & $3.34 \pm 0.9$ & $2.25 \pm 1.3$ \\
\hline & LF (\%) & $34.8 \pm 4.6)$ & $29.3 \pm 8.3$ \\
\hline & HF (\%) & II. $70 \pm 6.6$ & $13.0 \pm 5.7$ \\
\hline & VLF (\%) & $51.7 \pm 2.8$ & $56.4 \pm \mid 1.2$ \\
\hline & SI* & $80.61 \pm 80.2$ & $190.42 \pm 132.4$ \\
\hline & AMo (\%)* & $46.70 \pm 0.9$ & $60,80 \pm 9.5$ \\
\hline & TP* & $2157 \pm 1820$ & $854 \pm 720$ \\
\hline & $S^{*}$ & $\mid .57 \pm 0.5 \mathrm{|}$ & $3.2 \pm 0.8$ \\
\hline & JSL* & $0.5 I \pm 0.09$ & $0.36 \pm 0.14$ \\
\hline & JSR* & $0.49 \pm 0.8$ & $0.40 \pm 0.11$ \\
\hline \multirow{10}{*}{ Women } & LF/HF* & $1.21 \pm 0.6$ & $1.1 \pm 1.0$ \\
\hline & LF (\%)* & $29.35 \pm 4.8$ & $20.75 \pm 6.0$ \\
\hline & HF (\%)* & $26.95 \pm 8.9$ & $19.2 \pm 7.2$ \\
\hline & VLF (\%)* & $41.15 \pm 4.3$ & $59.5 \pm 9.0$ \\
\hline & $\mathrm{SI} *$ & $89.70 \pm 48.1$ & $179.14 \pm|2| .4$ \\
\hline & AMo (\%)* & $44.85 \pm 4.5$ & $56.80 \pm 8.1$ \\
\hline & TP* & $|947 \pm 8| \mid$ & $859 \pm 530$ \\
\hline & $\mathrm{S}^{*}$ & $2.1 \pm 0.62$ & $3.6 \pm 1.2$ \\
\hline & JSL* & $0.66 \pm 0.25$ & $0.5 I \pm 0.12$ \\
\hline & JSR* & $0.65 \pm 0.2$ & $0.49 \pm 0.15$ \\
\hline
\end{tabular}

*significant difference at $\mathrm{p}<0.05$

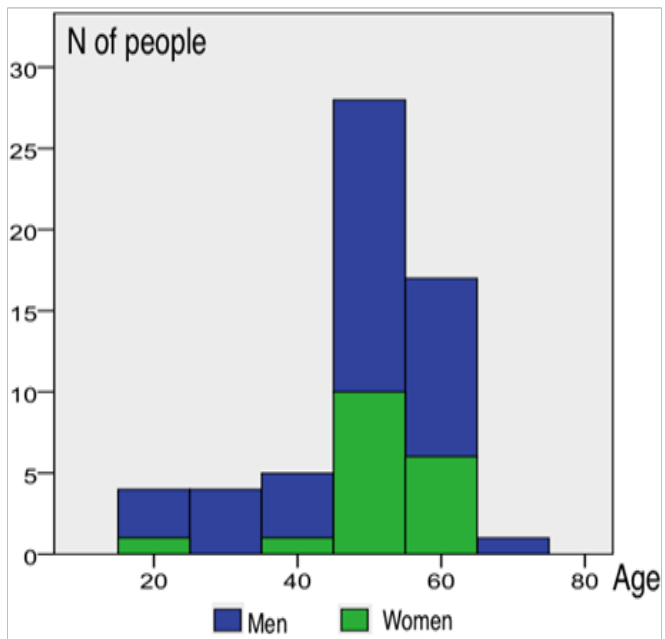

Figure I Frequency of occurrence of increased index of tension of regulatory systems for men and women depending on age.

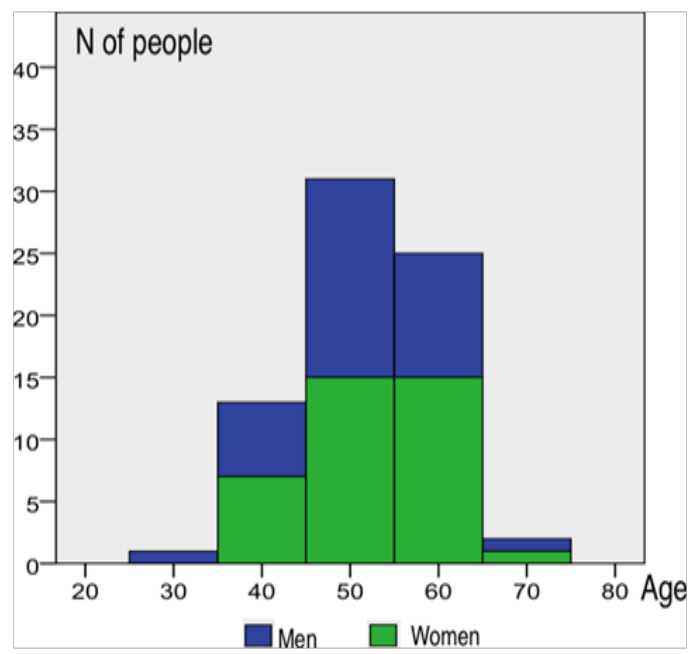

Figure 2 Frequency of occurrence of increased stress index for men and women depending on age.

Table 5 HRV Indices for men and women with normo-tone and sympathetic tone

\begin{tabular}{lllll}
\hline Index & $\begin{array}{l}\text { Men with normo- } \\
\text { tome }\end{array}$ & $\begin{array}{l}\text { Men with sympathetic } \\
\text { tone }\end{array}$ & $\begin{array}{l}\text { Women with normo- } \\
\text { tone }\end{array}$ & $\begin{array}{l}\text { Women with sympathetic } \\
\text { tone }\end{array}$ \\
\hline No. of people & 12 & 42 & 13 & 18 \\
LF/HF* & $1.81 \pm 0.13$ & $3.40 \pm 0.9$ & $1.66 \pm 0.04$ & $3.32 \pm 0.8$ \\
LF (\%) & $27.70 \pm 12$ & $32.90 \pm 10.4$ & $26.80 \pm 0.9$ & $29.00 \pm 0.8$ \\
HF (\%)* & $14.80 \pm 2.7$ & $9.04 \pm 3.1$ & $16.60 \pm 5.0$ & $10.25 \pm 4.0$ \\
\hline
\end{tabular}

\section{Conclusion}

i. Men had a shift in the autonomic balance toward the predominance of the sympathetic nervous system $(62.1 \%$ of studied population), while in women the autonomic balance is shifted toward predominance of the parasympathetic nervous system ( $75 \%$ of studied population).. This is valid both for healthy and hypertensive people. Moreover, for men lower activity of the parasympathetic center of the autonomic nervous center was observed.

ii. There were significant differences in GDV indexes. The integral area of luminescence of fingers of right and left hands (JSR, JSL), and the total area of the image (S), had lower values for men compared to women, which also indicates a bias in men of autonomic balance toward the sympathetic nervous system, and confirms the dependence of the GDV indexes on the activity of the autonomic nervous system.

iii. Hypertensive women differed from healthy ones by lower GDV parameters, which indicate the decrease in functional reserves of the organism and autonomic imbalance.

iv. For hypertensive women, unlike healthy ones, regulation of heart rate by autonomic reflex was less pronounced compared to regu- 
lation by low humoral-metabolic level. Similar changes in the regulation of cardiac rhythm for men with hypertension have been identified.

v. For patients with hypertension, regardless of gender, a high degree of centralization of heart rhythm regulation was found, which reflects the high activity of the sympathetic regulation mechanisms. However, this was not due to the increased activity of the sympathetic center, but due to the lower activity of the parasympathetic cardio-inhibitory center.

vi. More than half of studied population had high degree of centralization of heart rhythm regulation $(51.5 \%$ of men and $52.8 \%$ of women in all age groups).

\section{Acknowledgements}

None.

\section{Conflict of interest}

The author declares no conflict of interest.

\section{References}

1. Moiseev SV. Sympathetic nervous system and arterial hypertension: new approaches to treatment. Clinical pharmacology therapy. 2002;3(11):55-59.

2. Manual of hypertension. In: Chazov EI, et al. editors. "Media Medica", Netherlands: Publishing House; 2006. 325 p

3. Shlyakhto EV, Kondraty AO. Causes and consequences of the activation of the sympathetic nervous system in hypertension. Arterial hypertension. 2003;3(9):81-88.

4. Julius S, Krause L, Schork NJ, et al. Hyperkinetic borderline hypertension in Tecumseh, Michigan. J Hypertens. 1991;9(1):77-84.

5. Kuznetsova OB, Gorbunov NP. Gender peculiarities of autonomic reactions to mental workload of students with high level of physical activity. Theory and practice of physical culture. 2006;11:47-49.

6. Barnett SR, Morin RJ, Kiely DK, et al. Effects of age and gender on autonomic control of blood pressure dynamics. Hypertension. 1999;33(5):1195-1200.

7. Ramaekers $\mathrm{D}$, Ector $\mathrm{H}$, Aubert AE, et al. Heart rate variability and heart rate in healthy volunteers. Is the female autonomic nervous system cardioprotective? Eur Heart J. 1998;19(9):1334-1341.

8. Rossy LA, Thayer JF. Fitness and gender-related differences in heart period variability. Psychosom Med. 1998;60(6):773-781.

9. Sevre K, Lefrandt JD, Nordby G, et al. Autonomic function in hypertensive and normotensive subjects. The importance of gender. Hypertension. 2001;37(6):1351-1356.

10. Sato N, Miyake S. Cardiovascular reactivity to mental stress: relationship with menstrual cycle and gender. J Physiol Anthropol Appl Human Sci. 2004;23(6):215-223.

11. Dyachuk VA, Shanin VY, Svyatov DI. Gender differences in Central blood circulation at rest in the presence of a predisposition to hypertension. Vestnik St Petersburg University. 20018;11(1):24-26.

12. Zamotaev YN, Enikeev AH. Features of circadian rhythms of arterial pressure in individuals with hypertension in the factory conditions. Clinical medicine. 2010;2(88):30-35.
13. McCraty R, Shaffer F. Heart rate variability: new perspectives on physiological mechanisms, assessment of self-regulatory capacity, and health risk. Glob Adv Health Med. 2015;4(1):46-61.

14. Korotkov KG. Energy Fields Electrophotonic analysis in humans and nature. USA: eBookIt.com Publisher; 2002. 226 p.

15. Jakovleva E, Korotkov KG. Electrophotonic applications in medicine. GDV Bioelectrography. USA: US Trade Paper; 2013. 135 p.

16. Korotkov KG. Human Energy Field: Study with EPI Bioelectrography. Fair Lawn, USA: Backbone Publishing Co; 2002. 235 p.

17. Korotkov KG. Energy of Health. USA: Amazon.com Publishing; 2017. $287 \mathrm{p}$.

18. Korotkov KG, Matravers P, Orlov DV, et al. Application of electrophoton capture analysis based on gas discharge visualization technique in medicine: a systematic review. J Altern Complement Med. 2010;16(1):13-25.

19. Hossu M, Rupert R. Quantum events of biophoton emission associated with complementary and alternative medicine therapies. J Altern Complement Med. 2006;12(2):119-124.

20. Cohly H, Kostyuk N, Isokpehi R, et al. Bioelectrographic method for preventive health care. Biomedical science \& engineering conference, Oak Ridge, USA: First Annual ORNL; 2009. p. 1-4.

21. Rgeusskaja GV, Listopadov UI. Medical technology of electrophotonics-gas discharge visualization in evaluation of cognitive functions. $J$ Sci Healing Outcome. 2009;2(5):16-19.

22. Izabela Luiza Ciesielska Wróbel, Iwona Szadkowska, Józef Masajtis, et al. Images of corona discharges in patients with cardiovascular diseases as a preliminary analysis for research of the influence of textiles on images of corona discharges in Textiles' users. AUTEX Research Journal. 2010;10(1):26-30

23. Alexandrova R, Fedoseev G, Korotkov K, et al. Analysis of the Bioelectrograms of bronchial asthma patients. Proceedings of conference "Measuring the human energy field: State of the science". USA: National Institute of Health, Baltimore; 2003. p. 70-81.

24. Aleksandrova E, Zarubina T, Kovelkova M, et al. Gas discharge visualization (EPI) technique is new in diagnostics for patient with arterial hypertension. J New Med Technologies. 2010;17(1):122-125.

25. Polushin J, Levshankov A, Shirokov D, et al. Monitoring energy levels during treatment with EPI Technique. J Sci Healing Outcome. 2009;2(5):5-15.

26. Bundzen PV, Korotkov KG, Unestahl LE. Altered states of consciousness: review of experimental data obtained with a multiple techniques approach. J Altern Complement Med. 2002;8(2):153-165.

27. Korotkov KG, Korotkin DA. Concentration dependence of gas discharge around drops of inorganic electrolytes. i. 2001;89(9):4732-4736.

28. Augner C, Hacker GW, Schwarzenbacher S, et al. Gas Discharge Visualization (EPI): Eine auf physikalischen Methoden und Meridiananalysen basierende Technik zur Untersuchung von Stressreaktionen und energetischen Schwachstellen-Zwischenbericht laufender Forschung. Dt Ztschr F Akup (DZA). German J Acupuncture Related Techniques. 2010;53:14-20.

29. Korotkov K, Shelkov O, Shevtsov A, et al. Stress reduction with osteopathy assessed with GDV electrophotonic imaging: effects of osteopathy treatment. J Altern Complement Med. 2012;18(3):251-257.

30. Yakovleva EG, Buntseva OA, Belonosov SS, et al. Identifying patients with colon neoplasias with gas discharge visualization technique. $J \mathrm{Al}$ tern Complement Med. 2015;21(11):720-724. 